\title{
The Causes of the Distribution of Jian and Tuan Sounds in Linzhou Dialect
}

\author{
Jiahui Shen \\ School of Humanities, Tiangong University, Tianjin, China \\ Email: 2030141477@tiangong.edu.cn
}

How to cite this paper: Shen, J.H. (2021) The Causes of the Distribution of Jian and Tuan Sounds in Linzhou Dialect. Open Access Library Journal, 8: e7948.

https://doi.org/10.4236/oalib.1107948

Received: September 10, 2021

Accepted: October 12, 2021

Published: October 15, 2021

Copyright () 2021 by author(s) and Open Access Library Inc.

This work is licensed under the Creative Commons Attribution International License (CC BY 4.0).

http://creativecommons.org/licenses/by/4.0/

\section{(c) (i) Open Access}

\begin{abstract}
Based on the field investigation and combined with previous studies, this thesis makes a comprehensive description of the variation and distribution of jian and tuan sounds in Linzhou dialect. On this basis, the causes of the distribution are further explored from the perspective of sociolinguistics. Through the multidimensional investigation of the subjects and the general analysis of social and cultural factors, it is found that jian and tuan sounds are in the trend of merger and such a trend will continue to develop in the future. Besides, it is also found that the dialects in neighboring places as well as the impact of Standard Mandarin play a very important role in the merger progress.
\end{abstract}

\section{Subject Areas}

Linguistics

\section{Keywords}

Jian and Tuan Sounds, Linzhou Dialect, Sociolinguistics

\section{Introduction}

It is well-known that language is the most important tool of human thought. According to Hou Jingyi (1986) [1], Linzhou (林州) dialect belongs to Jin dialects. Chen Songya (2008) [2] once made comprehensive research on the speech sounds of Linzhou dialect. The merger of jian 尖 and tuan 团 sounds in it was pointed out in his paper. Since then, this issue has received more and more attention. However, many studies only make a rough sketch of jian and tuan sounds in Linzhou dialect, and the introduction about the distribution of them within Linzhou dialect area is not very clear. In addition, it must be pointed out that the 
research on the social and cultural factors affecting their distribution is not sufficient. However, a comprehensive study on this issue can be helpful to observe the evolutionary trend of the speech sounds in this area. It is also helpful to see how the social and cultural factors affect the evolution of a language. Therefore, it is of great significance to systematically research the distribution of the jian and tuan sounds in Linzhou dialect and explore the various factors accounting for this phenomenon. Thus, this research mainly deals with the following questions:

1) How jian and tuan sounds are distributed in Linzhou dialect?

2) What factors contribute to this phenomenon?

\section{Literature Review}

The notions of jian and tuan sounds were originally put forward in an ancient book named Yuan Yin Zheng Kao (《圆音正考》, 1743) [3], which was written by an unknown author and published in the Qing Dynasty, mainly discussing certain phonetic phenomena of Mandarin at that time with Manchu. Jian 尖 sounds are also known as Sharp sounds or the sounds of jing 精 group, which refer to some sound combinations ([ts], [ts], [dz], [s] or [z] with [i] or [y]) used to express some Chinese jing group characters (精组字), while tuan 团 sounds are some sound combinations $\left([\mathrm{k}],\left[\mathrm{k}^{\mathrm{c}}\right],[\mathrm{g}],[\mathrm{x}]\right.$ or $[\mathrm{\gamma}]$ with [i] or $\left.[\mathrm{y}]\right)$ used to express some Chinese jian group characters (见组字), and such sounds are also called Rounded sounds or the sounds of jian 见 group (Luo Futeng, 1996) [4]. According to Chen Songya (2008) [2], tuan sounds in Linzhou dialect have evolved into [tc], [tc'] and [6], while its jian sounds are [ts], [ts'] and [s], but some young people in Linzhou area pronounce jian-sound characters with tuan sounds. Namely, they merge jian sounds with tuan sounds together. By comparing the pronunciation of relevant words of Taiyuan (太原), Linzhou, Handan (邯郸), and Zhengzhou (郑州) and analyzing it from phonetic, geographic, and historical side, Chen demonstrated that such a merger is influenced by Zhongyuan dialects. By adopting the research methods of experimental phonetics, Gu Shaohua and Guo Shenqing (2015) [5] investigate the acoustic characteristics of jian and tuan sounds in Linzhou dialect. Meanwhile, the causes of their distribution are analyzed. However, the author believes that it is not sufficient to investigate jian and tuan sounds in Linzhou dialect only from the acoustic level. In addition, the language data provided in the paper is not enough, and most of the native subjects sought are from the northern area of Linzhou, while the southern area, as an important part of Linzhou, is not included in the study. Focusing on the rhyme type as a sound change condition to observe the jian and tuan sounds of Linzhou dialect, Qu Yanan (2016) [6] further described the distribution of them in Linzhou dialect and summarized the causes of such phenomenon. Besides, a more accurate analysis of the number and proportion of the Chinese characters with two pronunciations in the jing and jian group in Linzhou dialect is made. However, the subject selected for this research is a postgraduate (24 
years old) who is from Linzhou. That is to say, the number of the subjects being selected is limited. The language data used are not comprehensive and need to be further supplemented and improved. In general, the current research on the phenomenon of jian and tuan sounds in Linzhou dialect and its cause is mainly from the perspective of dialectology, and the study on it from the perspective of sociolinguistics needs to be further conducted.

\section{Methodology}

\subsection{Materials}

A questionnaire designed by the author according to the Word List for Surveys on Chinese Dialects ( 《方言调查字表》, 1981) [7] and Han's word list (Hanye, 2020) [8] is applied in the research. The questionnaire is used to test the locals' pronunciation of Chinese jian-sound characters and it includes two parts. The first part includes several personal questions, aiming at getting subjects' relevant background information that may affect their pronunciation. The second part is a word list, which forms the main part of the questionnaire. What is more, in order to improve the validity of the word list, a total of twenty-five jian-sound characters are selected by the author, which combined with other characters to form twenty-four words. Most words in the questionnaire have one jian-sound character except for the word “心情”, which is made up of two jian-sound characters.

The words 1, 2, 7, 8, 17, 18, 20 and 24 are used to test the subjects' pronunciation of some jian-sound characters whose pronunciation begins with [ts]. The words $4,5,10,11,12,13,19$ and 21 are used to test the subjects' pronunciation of some jian-sound characters whose pronunciation begins with [ $\mathrm{t}$ ' $]$. The words $3,6,9,14,15,16,22$ and 23 are used to test the subjects' pronunciation of some jian-sound characters whose pronunciation begins with [s].

\subsection{Subjects}

This study basically agrees with Chen's division of Linzhou dialect area (2008) [2], but some information needs to be updated. There are 16 towns in Linzhou. In this investigation, Linzhou dialect district was divided into three sub-districts based on the geographic location: southern district, northern district, and central district. Southern Linzhou refers to Chadian Town (茶店镇), Linqi Town (临淇 镇), and Wulong Town (五龙镇). Northern Linzhou refers to Rencun Town (任 村镇) and Donggang Town (东岗镇). The rest of eleven places belong to the central Linzhou, mainly including the urban area of Linzhou (林州市市区), Yaocun Town (姚村镇), Lingyang Town (陵阳镇), Hengshui Town (横水镇), Huanghua Town (黄华镇), Caisang Town (采桑镇), Yuankang Town (原康镇), et cetera.

The author interviewed some residents from Linzhou and divided them into three groups according to geographical factors. A total of eight subjects were selected for this survey. They are all undergraduate students who were born after 
1995. They had never left their hometown before thirteen years old, and they are able to speak Linzhou dialect very fluently. Their parents are the locals, and Linzhou dialect is frequently used in their lives until now. Therefore, they are ideal subjects. Figure 1 provides a clear description of their distribution:

In addition, a same questionnaire was initiated by the author on the Internet for the purpose of getting more information. A total of thirty questionnaires were finally collected and the information obtained from the online survey only serves as an additional reference. During the investigation, the author took full account of other social factors that may affect the validity of language data in the research, such as the language background of the family members, the life experience of the subjects, the place of residence, and the level of education. The influence of these variables is also fully considered in the survey. The selected subjects are all native subjects who live in the local area for a long time during the process of language acquisition and have little contact with people who speak other dialects.

\subsection{Procedures}

This research did a fieldwork in Linzhou dialect area. During the investigation, a semi-structured interview was conducted with each subject. During the interview, the researcher first conducts a casual conversation with the subject and asks him or her some questions relevant to himself or herself as well as their views on the local language for the sake of acquiring more background information. Then, the subject is asked to read the word list in Linzhou dialect. Meanwhile, the subject's pronunciations of these words are accurately recorded by the author. After the interview, all the corpora collected are systematically analyzed. And by comparing the phonetic survey data collected from three groups of subjects, an analysis on the distribution and variation of jian and tuan sounds and a systematic discussion about the factors for their formation are conducted.

\section{Findings}

Table 1 provides a group of pronunciation data of some jian-sound characters

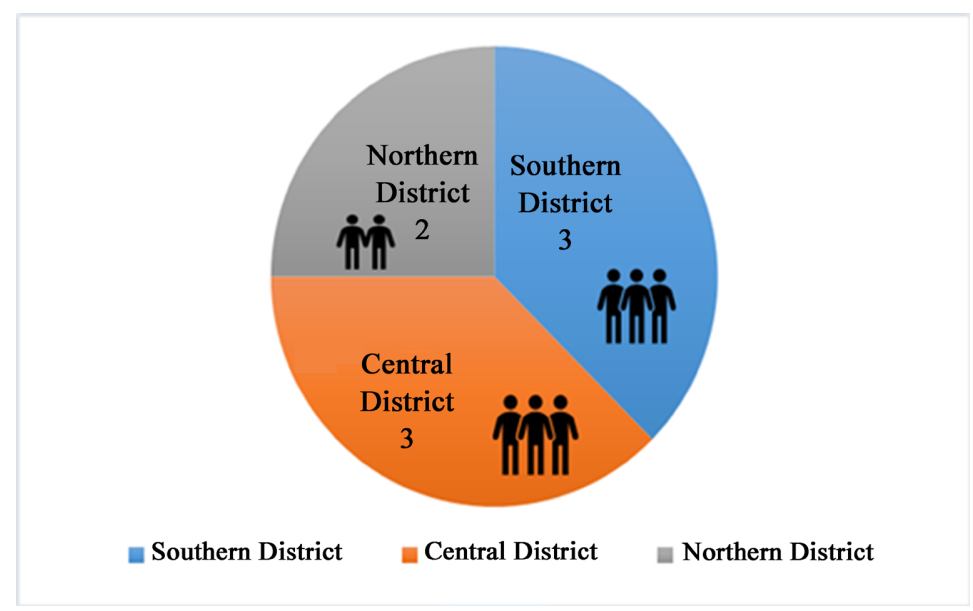

Figure 1. The distribution of the subjects. 
Table 1. The pronunciation of jian-sound characters of Linzhou area. ${ }^{1}$

\begin{tabular}{|c|c|c|c|}
\hline \multirow{2}{*}{ Characters } & \multicolumn{3}{|c|}{ Districts } \\
\hline & Southern Linzhou & Central Linzhou & Northern Linzhou \\
\hline 精 & tcin & tsin/țin & tsin/țin \\
\hline 清 & $t^{\mathrm{h}} \mathrm{in}$ & tshin & $t^{\mathrm{h}} \mathrm{in}$ \\
\hline 心情 & cin to $6^{h} i n$ & $\operatorname{cin} t_{6}^{h} i n / \sin t^{h}{ }^{h} i n$ & $\sin t_{6}^{h} i n$ \\
\hline 聚 & tcy/tsy & tcy/tsy & tcy/tsy \\
\hline 取 & $t^{\mathrm{h}} \mathrm{y}$ & $t^{\mathrm{h}} \mathrm{y} / \mathrm{t}^{\mathrm{h}} \mathrm{y}$ & $t^{\mathrm{h}} y / \mathrm{s}^{\mathrm{h}} \mathrm{y}$ \\
\hline 需 & 6y & sy/6y & 6y \\
\hline 癣 & sya & sya/6ya & 6уа \\
\hline
\end{tabular}

${ }^{1}$ The speech sound "/in/" in Standard Mandarin is pronounced as “/in/” in Linzhou dialect.

which was collected from the three subdistricts. According to Table 1, jian sounds merge with tuan sounds in each subarea. Besides, it was found that the pronunciations of local inhabitants from three districts are very different from each other. The pronunciations of the jian-sound characters in the southern Linzhou are quite different from those of northern Linzhou, and the pronunciations in the central Linzhou are relatively complex than those of other two places.

The data collected from the southern native subjects shows that there is a merger of jian and tuan sounds. In other words, most of the jian-sound characters have pronounced with tuan sounds in southern Linzhou. For instance, the word “心情” once was pronounced as [sin ts ${ }^{\text {hin] }}$ in Linzhou dialect. At the moment, people living in southern Linzhou pronounce it as [6in to $\left.{ }^{\mathrm{h}} \mathrm{in}\right]$. However, the author also noticed that not all jian-sound characters have been pronounced with tuan sounds. Namely, certain words have not influenced by the trend of merger. For example, many southern people still pronounce the Chinese character “癬” with jian sound [sya].

The data collected from the northern district shows that some jian-sound characters have changed its original pronunciation and become the same pronunciation as the corresponding tuan-sound character. The words “清” “情” “需” and “癬” are the best examples. The word “清” is a jian-sound character, whose pronunciation was [ $\left[\mathrm{s}^{\mathrm{h}} \mathrm{in}\right]$, but now it has been pronounced as a tuan sound [t6 ${ }^{\text {hin] }}$. Some words' pronunciations are merging with tuan sounds. Hence, they have two pronunciations now. For example, the characters “精” “聚” and “取” have two pronunciations respectively, while others still maintain their original pronunciations. From Table 1 it can be seen that the word “心” still keeps its original pronunciation [sin]. To sum up, it can be seen that there is a trend of merger in northern people's pronunciation.

Compared with the southern and northern Linzhou, Table 1 shows that the pronunciations of jian-sound characters in central Linzhou are relatively complex. Overall, most of the original pronunciations of Chinese jian-sound characters still exist in the central Linzhou dialect. Nevertheless, their corresponding 
tuan-sound pronunciations have accepted by a group of young people. Many words have two pronunciations. For example, both the sounds [sy] and [cy] can be used to express the word "需”, and the sounds [tsin] and [tcin] are the pronunciations of the word “精”. In order to clarify this result, more information needs to be provided. First of all, it must be pointed out that during the interview, two subjects from the central area express that the “精” in “精神” can be pronounced with two ways: [tsin] and [tcin]. Both pronunciations are acceptable to them, the same as the words “聚” “取” and “需” et cetera. Besides, online questionnaire survey shows that some subjects who were born after 2000 are also inclined to pronounce these words with tuan sounds. For example, they pronounce "取" as [t $6^{\mathrm{h} y}$ ], but it seems that some subjects from central area who were born in 1970s are more inclined to pronounce these characters with their original sounds. The causes contributing to this phenomenon will be discussed later.

To conclude, in terms of the pronunciation of jian-sound characters, the pronunciations of southern Linzhou are obviously opposite from those of central Linzhou and northern Linzhou. The jian and tuan sounds in southern Linzhou have already converged except for the pronunciations of certain words, while the northern Linzhou shows a tendency to converge, as some Chinese jian-sound characters have been pronounced with tuan sounds. As for the central area, although many jian-sound characters still maintain their original pronunciation, the pronunciations of the young adults in this place indicate an evident and strong tendency of merger.

\section{Discussion}

According to Linzhou Chorography (《林县志》, 1989) [9], most of the ancestors of Linzhou people came from Shanxi province. In the Ming Dynasty, they migrated to Linzhou. Linzhou is located in Tai-hang mountains area and the transportation was inconvenient in the past. To some extent, such a relatively closed environment allows Linzhou dialect to maintain its original phonetic characteristics for a long time.

According to the data obtained, it can be found that the southern Linzhou dialect area almost does not retain jian sounds anymore, while the northern and central areas still retain many jian sounds. According to Gu and Guo's research (2015) [5], Linzhou dialect is just in a transitional zone between two kinds of dialect areas. One is the dialect area with jian and tuan sounds, and the other is the dialect area with the merger of jian and tuan sounds (Gu Shaohua \& Guo Shenqing, 2015) [5]. Huixian City (辉县市), Weihui City (卫辉市) and Qi County (淇 县) are close to the southern part of Linzhou, and there are no jian sounds in their pronunciations, while Pingshun County (平顺县) and Huguan County (䡬 关县) are near the western and northern parts of Linzhou, and jian sounds still can be found in the locals' pronunciation (Gu Shaohua \& Guo Shenqing, 2015) [5].

Besides, due to the close distance, frequent economic and cultural exchanges 
have been conducted between these places and Linzhou City. During this process, the dialects in Huixian City, Weihui City, and Qixian County impact greatly on the southern Linzhou dialect, which is viewed as one of main factors leading to the southern Linzhou people no longer expressing their ideas with jian sounds.

As for the central and northern parts of Linzhou, on one hand, jian sounds exist in Linzhou dialect from the beginning. On the other hand, the dialect in central and northern parts of Linzhou is influenced by other Jin dialects with jian and tuan sounds next to Linzhou. For example, the central and northern Linzhou has established close economic and cultural relations with Pingshun County, Huguan County and other places. Each year many migrant workers from Linzhou work in Pingshun County, Huguan County, and other places in Shanxi province, which are close to central and northern Linzhou. And as mentioned earlier, the dialects of these places still have jian sounds. Therefore, most people in central and northern Linzhou still maintain jian sounds in their pronunciation.

Last but not least, it is believed that the promotion of Standard Mandarin in recent decades contributes greatly to such a phenomenon, especially to the merger occurring in central and northern Linzhou. A further analysis is needed on this point. In this investigation, most subjects were born in the Internet age when China's economy starts booming, so does the Linzhou area, which means a better life, better education, better transportation, and hence frequent communication with the world outside Linzhou. What is more, under the influence of Standard Mandarin promotion program, Putonghua has entered the local education system as a powerful dialect at this time. It is used as a medium of teaching and students are encouraged to use Standard Mandarin in schools to the extent that some of them even said that they would feel a little unaccustomed and earthy if they answer teachers' question in the local language. On that note, it indicates that Standard Mandarin plays a very important role in both the local educational system and the youngers' daily life. However, it is well-known that in Standard Mandarin, the Chinese jian-sound characters are pronounced with tuan sounds. Therefore, under the combined effect of these factors, especially the impact of Standard Mandarin, a process of merger between jian and tuan sounds has begun in Linzhou Dialect.

\section{Conclusion}

By conducting a fieldwork, this article systematically introduces the distribution of jian and tuan sounds in Linzhou dialect and explores the social and cultural factors contributing to the distribution from the perspective of sociolinguistics. It is found that the distribution of jian and tuan sounds in Linzhou dialect area is imbalanced. The jian and tuan sounds in southern Linzhou dialect area almost have already converged. In the northern and central area, some Chinese jiansound characters have been pronounced with tuan sounds, which shows a ten- 
dency of merger. What is more, the dialects in neighboring places and the influence of Standard Mandarin play a pivotal role in the merger process. Hence it is presumed that such a phenomenon will develop further in the future. Different from previous studies, this thesis analyzes jian and tuan sounds in Linzhou dialect from the sociolinguistic side. Many fresh and authentic corpora are collected during the field work, and the findings are critical for understanding the evolution and distribution of jian and tuan sounds within Linzhou dialect area. However, it must be pointed out that this study has certain limitations. Due to limited time and energy, the subjects and dialect points selected in this survey are limited, which may miss some important information and corpora. Moreover, it is found that it is also of great significance to discuss the merger of jian and tuan sounds in Linzhou dialect from the perspective of phonology. In the future, the jian and tuan sounds in Linzhou dialect can be further explored and perhaps more valuable phonetic evolution laws will be found.

\section{Conflicts of Interest}

The author declares no conflicts of interest.

\section{References}

[1] 侯精一. 晋语的分区(稿) [J]. 方言, 1986(4): 253-261.

[2] 陈松亚. 林州方言语音研究[D]: [硕士学位论文]. 重庆: 西南大学, 2008. https://kns.cnki.net/KCMS/detail/detail.aspx?dbname=CMFD2008\&filename $=2008$ 093120.nh

[3] 存之堂辑. 圆音正考(刻本) [M]. 北京: 京都三槐堂, 1743.

[4] 罗福腾. “尖团音”概念订误[J]. 语言教学与研究, 1996(1): 67-72.

[5] 谷少华, 郭沈青. 林州方言尖团音分混现状及其成因 [J]. 殷都学刊, 2015(4): 107-111. https://doi.org/10.16140/j.cnki.ydxk.2015.04.021

[6] 渠亚楠. 林州方言尖团音分合情况考探 [J]. 忻州师范学院学报, 2016(6), 120-123.

[7] 中国社会科学院语言研究所. 方言调查字表(修订本) [M]. 北京: 商务印书馆, 1981.

[8] 韩烨. 河北㩰城方言尖团音变异研究[D]: [硕士学位论文]. 北京: 北京外国语大 学, 2020 .

https://kns.cnki.net/KCMS/detail/detail.aspx?dbname $=$ CMFD202101\&filename $=10$ 20078822.nh

[9] 张旺增. 林县志 $[M]$. 郑州: 河南人民出版社, 1989. 


\section{Appendix}

The boldfaced characters in the questionnaire are Chinese jian-sound characters.

\begin{tabular}{ll}
\hline \multicolumn{1}{c}{ Questionnaire } \\
\hline 1 & \multicolumn{1}{c}{ Part 1: Personal Questions } \\
\hline 2 & 您的名字是? \\
3 & 您的性别是? \\
4 & 您来自哪里? (具体地址) \\
5 & 您的学历是? \\
6 & 您的出生年份是? \\
7 & 您在 13 岁之前有没有长期外出林州市经历? \\
& 您的父母都是林州本地人吗? \\
\hline
\end{tabular}

Part 2: Word List

\begin{tabular}{|c|c|c|c|}
\hline 1. 聚会 & 2. 赶集 & 3. 牛皮痽 & 4. 青草 \\
\hline 5. 喜鹊 & 6. 洗衣裳 & 7. 精神 & 8. 匠人 \\
\hline 9. 需要 & 10. 心情 & 11. 清楚 & 12. 有钱 \\
\hline 13. 全部 & 14. 元宵 & 15. 下雪 & 16. 感谢 \\
\hline 17. 绝对 & 18. 红酒 & 19. 秋天 & 20. 推荐 \\
\hline 21. 可取之处 & 22. 迅速 & 23. 消除 & 24. 英俊 \\
\hline \multicolumn{4}{|c|}{ List of Some Subjects } \\
\hline Name & \multicolumn{2}{|c|}{ Place } & \\
\hline Yang Wen & \multicolumn{2}{|c|}{ Donggang Town } & \\
\hline Duan Keqin & \multicolumn{2}{|c|}{ Donggang Town } & \\
\hline Yang Pei & \multicolumn{2}{|c|}{ Lingyang Town } & \\
\hline Shen Xinhui & \multicolumn{2}{|c|}{ Yaocun Town } & \\
\hline Shen Xingwei & \multicolumn{2}{|c|}{ Yaocun Town } & \\
\hline Liu Haoran & \multicolumn{2}{|c|}{ Huanghua Town } & \\
\hline Hu Honghong & \multicolumn{2}{|c|}{ Huanghua Town } & \\
\hline Wang Xiaobei & \multicolumn{2}{|c|}{ The urban area of Linzhou } & \\
\hline Li Zepeng & \multicolumn{2}{|c|}{ The urban area of Linzhou } & \\
\hline Li Wei & \multicolumn{2}{|c|}{ The urban area of Linzhou } & \\
\hline Wang Shufang & \multicolumn{2}{|c|}{ The urban area of Linzhou } & \\
\hline Zhang Biyu & \multicolumn{2}{|c|}{ The urban area of Linzhou } & \\
\hline Shen Guoxiang & \multicolumn{2}{|c|}{ The urban area of Linzhou } & \\
\hline Wang Ru & \multicolumn{2}{|c|}{ Chadian Town } & \\
\hline Wang Linhui & \multicolumn{2}{|c|}{ Chadian Town } & \\
\hline Jing Li & \multicolumn{2}{|c|}{ Yuankang Town } & \\
\hline Yuan Wenli & \multicolumn{2}{|c|}{ Yuankang Town } & \\
\hline
\end{tabular}




\section{Continued}

\begin{tabular}{ll}
\hline Wang Jundong & Caisang Town \\
Hao Ziyin & Dongyao Town \\
Wang Rong & Guilin Town \\
Wang Yao & Guilin Town \\
Feng Peilong & Wulong Town \\
Ren Linhao & Wulong Town \\
Wang Huichao & Linqi Town \\
Li Dongfei & Linqi Town \\
Wan Zixv & Linqi Town \\
\hline
\end{tabular}

